\title{
Research
}

\section{piRNA-mediated transgenerational inheritance of an acquired trait}

\author{
Thomas Grentzinger, ${ }^{1}$ Claudia Armenise, ${ }^{1}$ Christine Brun, Bruno Mugat, \\ Vincent Serrano, Alain Pelisson, and Séverine Chambeyron ${ }^{2}$ \\ Institut de Génétique Humaine, CNRS, 34396 Montpellier CEDEX 5, France
}

\begin{abstract}
The maintenance of genome integrity is an essential trait to the successful transmission of genetic information. In animal germ cells, piRNAs guide PIWI proteins to silence transposable elements (TEs) in order to maintain genome integrity. In insects, most TE silencing in the germline is achieved by secondary piRNAs that are produced by a feed-forward loop (the pingpong cycle), which requires the piRNA-directed cleavage of two types of RNAs: mRNAs of functional euchromatic TEs and heterochromatic transcripts that contain defective TE sequences. The first cleavage that initiates such an amplification loop remains poorly understood. Taking advantage of the existence of strains that are devoid of functional copies of the LINE-like l-element, we report here that in such Drosophila ovaries, the initiation of a ping-pong cycle is exclusively achieved by secondary l-element piRNAs that are produced in the ovary and deposited in the embryonic germline. This unusual secondary piRNA biogenesis, detected in the absence of functional l-element copies, results from the processing of sense and antisense transcripts of several different defective l-element. Once acquired, for instance after ancestor aging, this capacity to produce heterochromatic-only secondary piRNAs is partially transmitted through generations via maternal piRNAs. Furthermore, such piRNAs acting as ping-pong initiators in a chromatin-independent manner confer to the progeny a high capacity to repress the l-element mobility. Our study explains, at the molecular level, the basis for epigenetic memory of maternal immunity that protects females from hybrid dysgenesis caused by transposition of paternally inherited functional l-element.
\end{abstract}

[Supplemental material is available for this article.]

Repetitive sequences, especially transposable elements (TEs), represent a large fraction of almost every eukaryotic genome (Lander et al. 2001; Biemont and Vieira 2006). Since their propagation can be highly deleterious for the host, especially in the germline, metazoa have developed a strategy to silence TEs through a smallRNA-based defense system in which proteins from the PIWI clade of the ARGONAUTE family and their associated PIWI-interacting RNAs (piRNAs) can recognize and silence complementary TE targets (for review, see Saito and Siomi 2010; Senti and Brennecke 2010; Siomi et al. 2011).

During evolution, most TEs seem to have accumulated "dead" defective copies in Drosophila pericentromeric heterochromatin. The functional significance of these "graveyards" remained elusive until the observation that pericentromeric heterochromatin contains master control loci that produce defective-TE-rich transcripts that are processed into 23- to 29-nucleotide (nt)-long primary piRNAs (Brennecke et al. 2007).

In the Drosophila female germline, the repression of functional TEs is linked to the production of large amounts of secondary piRNAs (Brennecke et al. 2007; Gunawardane et al. 2007) by a feed-forward amplification loop, termed the ping-pong cycle, based on the interplay between defective and functional copies of each TE. According to the established model, antisense primary piRNAs, which are produced by defective heterochromatic TEs, guide their PIWI endonucleases to the complementary sense transcripts of the functional euchromatic TEs. The resulting cleavage produces sense secondary piRNAs that, in turn, can guide the

\footnotetext{
${ }^{1}$ These authors contributed equally to this work.

${ }^{2}$ Corresponding author

E-mail severine.chambeyron@igh.cnrs.fr

Article published online before print. Article, supplemental material, and publication date are at http://www.genome.org/cgi/doi/10.1101/gr.136614.111.
}

slicing of heterochromatic transcripts to produce antisense secondary piRNAs, and so on. Since PIWI endonucleases cleave $10 \mathrm{nt}$ from the $5^{\prime}$ end of their associated piRNAs, both sense and antisense piRNA partners of a ping-pong pair can be recognized by the characteristic 10-nt overlap, defined as the ping-pong signature (Brennecke et al. 2007; Gunawardane et al. 2007).

As secondary piRNAs are usually required for the complete repression of functional TEs in the germline, the cooperation of both defective heterochromatic and functional euchromatic copies of a given TE seems to be necessary for mounting an efficient piRNA-mediated defense against the TE functional copies.

Such cooperation was described in Drosophila melanogaster for the I-element, a germinal-specific LINE-like TE (Brennecke et al. 2008; Chambeyron et al. 2008). During its evolutionary history, D. melanogaster was invaded at least twice by the I-element (Bucheton et al. 1992) resulting in two classes of strains: inducer (I) and reactive (R). R strains were preserved from the second invasion by their anterior isolation in fly laboratories. Several lines of evidence have previously demonstrated that their genome only contains vestiges of the first invasion, consisting of dozens of defective I-element copies that are located in pericentromeric heterochromatin and cannot transpose (Bucheton et al. 1984; Pelisson and Bregliano 1987; Vaury et al. 1989, 1990; Chambeyron et al. 2002). In contrast, the genome of I strains contains additional euchromatic insertions of functional I-elements capable of invading the genome (Bucheton et al. 1976, 1984). These I-elements do not transpose efficiently in I strains, because of the presence of high amounts of piRNAs that are amplified by ping-pong between hetero- and euchromatic I-element transcripts in the female germline (Brennecke et al. 2008; Chambeyron et al. 2008).

The cooperation between hetero- and euchromatic I-element transcripts operates efficiently only if the functional I-elements are also present in the mothers. Indeed, the so-called RSF (Reciprocal 
Sterile Female) female progeny of I mothers and $\mathrm{R}$ fathers can produce enough piRNAs to achieve I-element repression; conversely, the reciprocal cross generates dysgenic females (called SF, for sterile females) that do not produce detectable amounts of I-element piRNAs and therefore accumulate high amounts of I-element messenger RNAs in the vicinity of the nucleus where retrotransposition can occur (Chambeyron et al. 2008). The maternal contribution was assumed to correspond to the deposition of I-element piRNAs in the embryonic germline of RSF females (Brennecke et al. 2008).

Previous genetic studies reported that the fertility of SF females can be improved by various aging and thermic treatments applied not only on the SF females themselves but also on their $\mathrm{R}$ mothers (Bucheton 1978). The effect of such treatments is maternally inherited but is progressively lost over generations (Bucheton 1979; Bucheton et al. 2002; Chambeyron and Bucheton 2005). Environmental factors can therefore modify the epigenetic characteristics of $\mathrm{R}$ females, as an acquired trait that can be partially transmitted to the progeny. We thus hypothesized that piRNA populations could be major players in this transgenerational epigenetic inheritance.

We report here the detection of secondary I-element piRNAs in the ovaries of $\mathrm{R}$ and SF females derived from aged ancestors. We also show that the production of R-specific secondary piRNAs, in the absence of any functional I-element, results from ping-pong amplification loops between many defective heterochromatic I-elements. We present evidence that the ability to produce secondary piRNAs in the ovaries of $\mathrm{R}$ females is an epigenetic trait that, once acquired upon aging treatment, can be transmitted through several maternal generations. Indeed, our data demonstrate that the maternal deposit of piRNAs in the embryonic germ cells directly primes the amplification loop of homologous secondary piRNAs in the ovaries of the progeny, without affecting the primary biogenesis.

\section{Results}

An inheritable age-induced defense system against functional I-element expression

To study the molecular basis of the partial rescue of SF sterility after ancestor aging of R strains, we split the Cha R strain into two fly stocks. The "short-generation stock" was bred with flies that were always obtained from young parents (3-d-old females); the "longgeneration stock," with flies continuously obtained from aged parents (25-d-old females for at least five generations) (Fig. 1A; Supplemental Methods).

We then crossed 3-d-old R females from both stocks with inducer males of the isogenic Cha-I strain (see Methods; Pelisson and
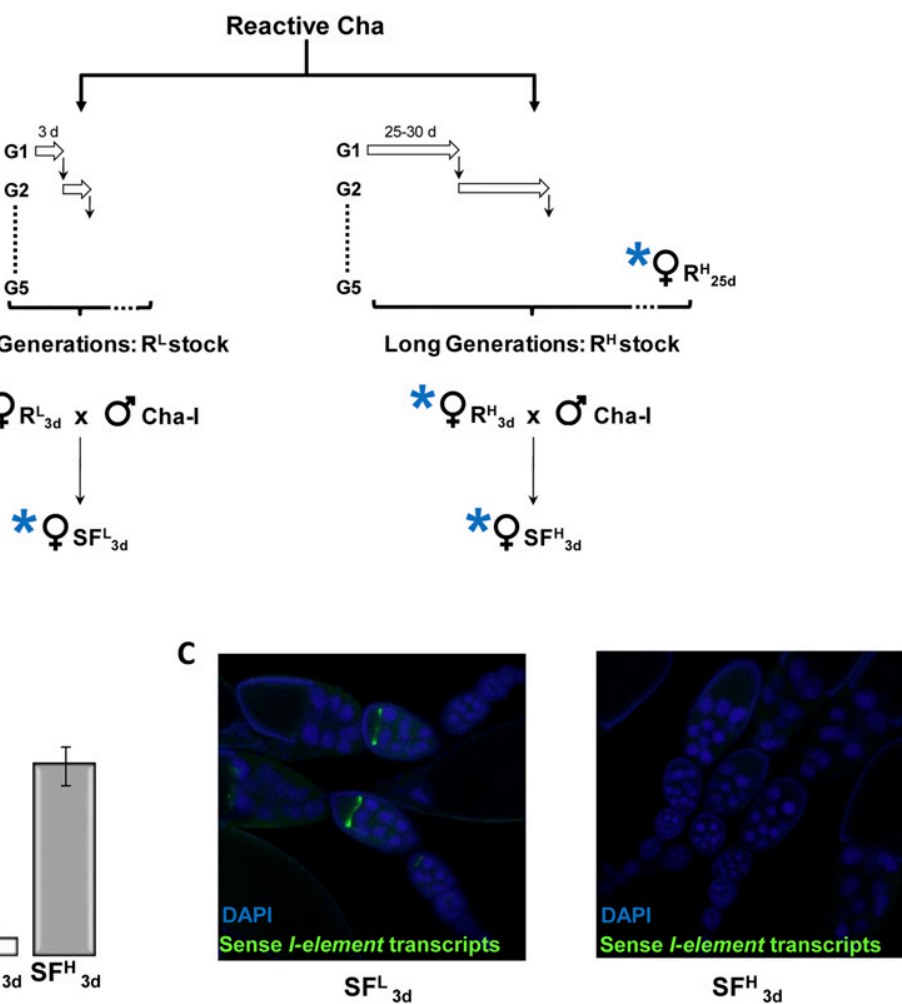

Figure 1. The rescue of SF sterility induced by aging treatment of the maternal ancestors correlates with l-element repression. $(A)$ Schematic representation of the biological model. The reactive (R) Cha

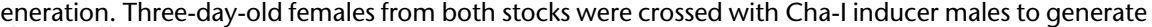

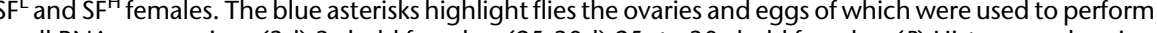
small RNA sequencing. (3d) 3-d-old females; (25-30d) 25- to 30-d-old females. (B) Histogram showing labeled antisense riboprobe specific for I-element sense transcripts. I-element sense transcripts were detected (green) only in oocytes of $\mathrm{SF}^{\mathrm{L}}$ ovaries. Ovaries were counterstained with DAPI (blue).

Bregliano 1987) and assessed the fertility of the progeny (Fig. 1A,B). $\mathrm{SF}$ females with aged $\mathrm{R}$ maternal ancestors (for at least five generations) were significantly more fertile than SF females with young R maternal ancestors $\left(P=10^{-12}\right)$ (Fig. 1B). This fertility increase correlated with I-element repression in the SF germline. Indeed, in situ hybridization experiments on whole-mount ovaries showed that I-element transcripts were accumulated at the anterior pole of oocytes in sterile SF females, whereas they were not detected in fertile SF flies, the ancestors of which were aged (Fig. 1C). Therefore, we designated the short-generation stock as "L" and the longgeneration one as " $\mathrm{H}$ " (for respectively Low and High capacity to repress the I-element).

These results indicate that in these two isogenic lineages, the capacity to repress I-element expression is tightly linked to the ancestor aging treatment.

Establishment of an efficient piRNA-mediated silencing of the l-element in the dysgenic female progeny of aged ancestors

We next compared the ovarian piRNA populations of 3-d-old isogenic $\mathrm{SF}^{\mathrm{L}}\left(\mathrm{SF}_{3 \mathrm{~d}}^{\mathrm{L}}\right)$ females (with young $\mathrm{R}$ ancestors) and $\mathrm{SF}^{\mathrm{H}}\left(\mathrm{SF}^{\mathrm{H}}{ }_{3 \mathrm{~d}}\right)$ females (with aged $\mathrm{R}$ ancestors). In order to enhance the quality of 
our libraries, we used an anion exchange chromatography strategy to purify protein-associated small RNAs as previously described (see Supplemental Methods; Lau et al. 2009). This approach depletes RNA degradation products and decreases the amount of $2 \mathrm{~S}$ rRNA, the main Drosophila contaminant, in sequenced libraries (Supplemental Fig. S1). To account for differences in sequencing quality and depth, we normalized the small RNA populations to 1 million piRNAs as previously published (Handler et al. 2011; see Methods; Supplemental Methods). This normalization strategy is optimal for minimizing the differences between libraries (Supplemental Fig. S2).

The levels of ovarian piRNAs from each of the 85 major TEs were highly similar in both isogenic libraries (Fig. 2A). As expected, the I-element showed the largest difference, with a 2.9-fold increase in I-element piRNA levels in $\mathrm{SF}_{3 \mathrm{~d}}^{\mathrm{H}}$ ovaries compared with $\mathrm{SF}_{3 \mathrm{~d}}^{\mathrm{L}}$ ovaries (Fig. 2B, Supplemental Table S1). This increase concerned both sense and antisense I-element piRNA populations along the whole I-element sequence (Supplemental Fig. S3A). Both perfectly matching I-element piRNAs (mainly resulting from post-transcriptional processing of functional I-element transcripts) and the mismatching I-element piRNAs (exclusively coming from defective I-element transcripts) were increased (Supplemental Fig. S3B). Moreover, I-element piRNAs exhibited a classic ping-pong signature in $\mathrm{SF}_{3 \mathrm{~d}}^{\mathrm{H}}$ ovaries but not in $\mathrm{SF}^{\mathrm{L}}{ }_{3 \mathrm{~d}}$ ovaries, and this feature was correlated with I-element repression (Fig. 2C). This finding is consistent with previous data showing a link among I-element piRNA accumulation, ping-pong signature, and I-element repression (Brennecke et al. 2008; Chambeyron et al. 2008). The ping-pong signatures for other TEs with dominant germline expression in ovaries from $\mathrm{SF}_{3 \mathrm{~d}}^{\mathrm{H}}$ and $\mathrm{SF}_{3 \mathrm{~d}}^{\mathrm{L}}$ were not increased (Supplemental Fig. S7A).
A

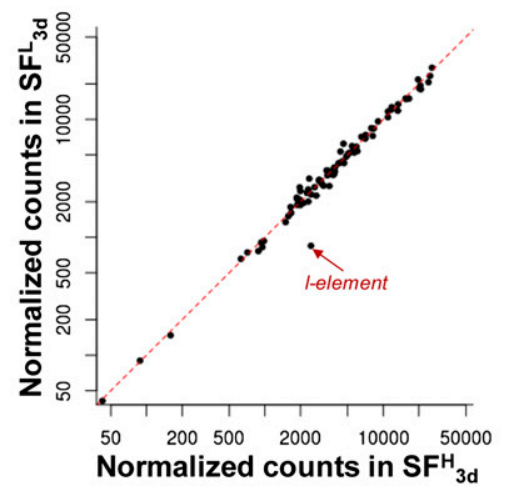

D

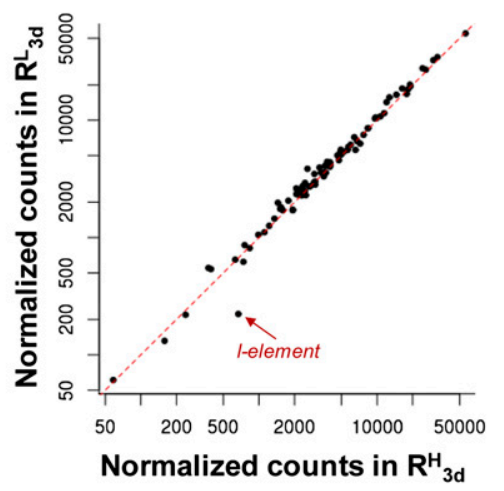

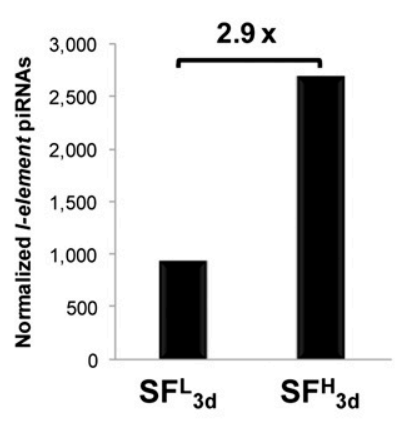

$\mathbf{E}$

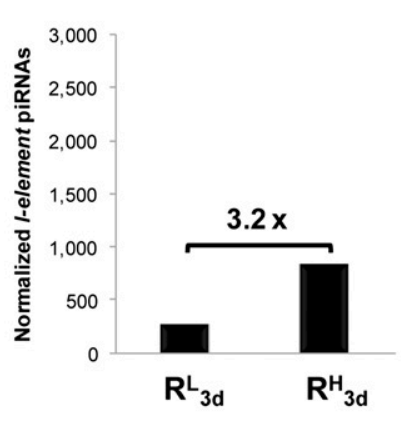

C
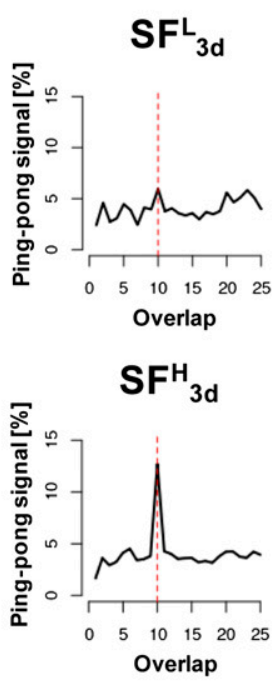

$\mathbf{F}$
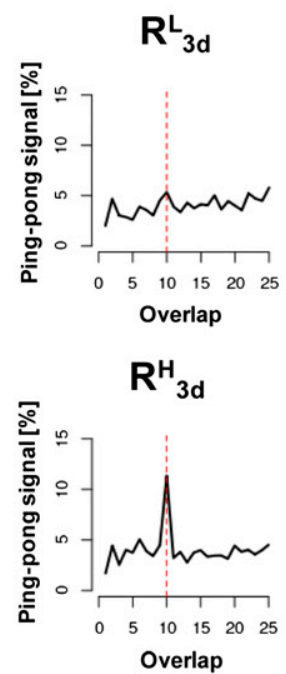

Figure 2. Aging treatment boosts the production of I-element piRNAs in the next generations. $(A, D)$ Pairwise comparison of the TE piRNA levels in ovaries from 3-d-old isogenic flies ( $\mathrm{SF}_{3 d}^{\mathrm{L}}, \mathrm{SF}_{3 \mathrm{~d}}$ and $\mathrm{R}_{3 \mathrm{~d}}, \mathrm{R}^{\mathrm{H}}{ }_{3 \mathrm{~d}}$ ) that have young or aged ancestors, respectively. Scatter plots display correlation between normalized piRNA abundances for each of the 85 most highly targeted Drosophila TEs (up to four mismatches allowed between reads and RepBase sequence). $(B, E)$ Normalized counts of ovarian I-element piRNAs shows that they are increased in the offspring of females with aged ancestors. (C, $F) A$ pingpong signature for the l-element could only be detected in the progeny of aged ancestors. 
Finally, bioinformatic analysis of previously published small RNA deep sequencing data (Brennecke et al. 2008) showed that, based on the amount of I-element piRNAs and the ping-pong signature, $\mathrm{SF}_{3 \mathrm{~d}}^{\mathrm{H}}$ females were similar to fertile RSF females, obtained by crossing R males with I females (Fig. 2B,C,; Supplemental Fig. S3C). Conversely, $\mathrm{SF}_{3 \mathrm{~d}}^{\mathrm{L}}$ females (characterized by low I-element piRNA amount and absence of ping-pong signature) (Fig. 2B,C) were comparable to previously described sterile SF females (Supplemental Fig. S3C).

In summary, these observations demonstrate that the aging of $\mathrm{R}$ ancestors over several successive generations results in a piRNAmediated repression of I-element expression in a SF cross that is almost as efficient as the repression previously described in a RSF cross.

\section{Ping-pong amplification can occur between defective I-elements in R strains}

The production of secondary I-element piRNAs in RSF females was assumed to depend on the piRNAs inherited from their I mothers (Brennecke et al. 2008). We therefore investigated whether I-element piRNAs accumulated in the $\mathrm{R}$ mothers of $\mathrm{SF}^{\mathrm{H}}{ }_{3 \mathrm{~d}}$ females by comparing the ovarian piRNA populations of $\mathrm{R}_{3 \mathrm{~d}}^{\mathrm{L}}$ (short -generation stock) and $\mathrm{R}_{3 \mathrm{~d}}^{\mathrm{H}}$ (long-generation stock) 3-d-old flies. In contrast to the relatively small differences in piRNA accumulation observed for the 85 studied TEs (Fig. 2D, Supplemental Table S1), I-element piRNA levels were 3.2-fold higher in $\mathrm{R}_{3 \mathrm{~d}}^{\mathrm{H}}$ than in $\mathrm{R}^{\mathrm{L}}$ ovaries (Fig. 2E). This increase concerned both sense and antisense I-element piRNA populations along the I-element sequence (Supplemental Fig. S5A). The increase of I-element piRNAs by maternal aging was not associated with changes in PIWI protein levels (Supplemental Fig. S4). Moreover, for the first time, we detected a ping-pong signature for the I-element in R ovaries $\left(\mathrm{R}_{3 \mathrm{~d}}^{\mathrm{H}}\right.$ in Fig. $\left.2 \mathrm{~F}\right)$, indicating that aging over several generations results in active I-element secondary biogenesis in the progeny.

To further characterize this phenomenon, we split the I-element piRNA populations into piRNAs that had at least one sequenced ping-pong partner (i.e., another piRNA containing a reverse complementary 5' 10-mer; see Methods) and all the others (Fig. 3A). The first class is likely to correspond to secondary piRNAs, while the piRNA class without a sequenced ping-pong partner consists of both primary piRNAs and secondary piRNAs, the pingpong partners of which were not sequenced due to the limited sequencing depth. As shown in Figure 3A and Supplemental Figure $\mathrm{S} 5 \mathrm{~B}$, the increase of I-element piRNA level in $\mathrm{R}_{3 \mathrm{~d}}^{\mathrm{H}}$ Ovaries was likely due to ping-pong amplification.

The population of I-element piRNAs with ping-pong partners exhibited a strong nucleotide-strand bias (80\% of antisense piRNAs had a uridine [U] at position 1 and $80 \%$ of sense piRNAs had an adenosine $[\mathrm{A}]$ at position 10) (Supplemental Fig. S5C). So, in R strains that are devoid of functional I-element, sense secondary piRNAs mainly had an adenosine at position 10 , a feature previously observed for I-element piRNAs produced in I strains by processing of functional I-element transcripts (Brennecke et al. 2008). Hence, the ping-pong amplification in R strains could be achieved by heterochromatic-defective I-element transcripts behaving just like the functional transcripts of euchromatic I-elements in I strains, by producing sense I-element piRNAs with an adenosine at position 10 .

To determine whether a specific defective I-element fragment played the role of the "functional-like" I-element in $\mathrm{R}^{\mathrm{H}}{ }_{3 \mathrm{~d}}$ ovaries and could thus potentially trigger an efficient secondary bio- genesis through the production of 10A sense piRNAs, we computed the amount of secondary piRNAs originating from each of the I-element defective fragments that have been annotated in the Drosophila genome (Fig. 3B). Here we identified that, in $\mathrm{R}_{3 \mathrm{~d}}^{\mathrm{H}}$ ovaries, many I-element defective fragments produce secondary piRNAs in sense and antisense orientation according to the functional I-element sequence (Fig. 3B; Supplemental Fig. S6). Interestingly, we also determined that the ping-pong loops between heterochromaticdefective I-element transcripts mainly occur between transcripts that do not originate from the same heterochromatic-defective fragment (Supplemental Fig. S5D). Indeed, 90\% of the secondary piRNAs uniquely mapping to the genome have ping-pong partner(s) that belong to a defective I-element transcript coming from other genomic loci.

The ping-pong loop increase between heterochromaticdefective fragments is specific to I-element as secondary piRNAs coming from other germinal TEs do not seem to be affected (Supplemental Fig. S7B).

The $42 A B$ cluster is considered to be the major producer of genome-unique I-element piRNAs and a major regulatory locus for the I-element (Brennecke et al. 2008). We thus asked whether $42 A B$ derived I-element piRNAs were also highly sensitive to ancestor aging. Ancestor aging only induced a 2.2 -fold increase of $42 \mathrm{AB}$ derived I-element piRNAs in $\mathrm{R}^{\mathrm{H}}{ }_{3 \mathrm{~d}}$ compared with $\mathrm{R}_{3 \mathrm{~d}}^{\mathrm{L}}$, whereas the other genome-unique I-element piRNAs showed a 3.7-fold increase (Supplemental Fig. S5E). These results indicate that (1) despite their strong piRNA production, defective I-elements from the $42 \mathrm{AB}$ cluster were not more sensitive to ancestor aging than defective I-elements belonging to the other producer loci such as those located in 2RHet and $U$ chromosome arms; and (2) the increase of the secondary piRNA population in the $\mathrm{R}_{3 \mathrm{~d}}^{\mathrm{H}}$ library originated from most of, if not all, the defective I-element fragments (Fig. 3B).

Our observations provide evidence for a cryptic secondary piRNA biogenesis pathway that is boosted in the R female progeny of aged ancestors and involves many defective I-element fragments.

\section{The stimulation of secondary piRNA biosynthesis by maternal aging does not result from increased levels of l-element piRNA precursors}

Several chromatin-associated proteins were reported to modulate the efficiency of piRNA biogenesis in the Drosophila germline at the level of transcription and/ or processing of the heterochromatic RNA precursors (Klattenhoff et al. 2009; Rangan et al. 2011; Zamparini et al. 2011). We therefore asked whether the increased production of secondary piRNAs and its maternal inheritance could be due to modulation of transcription or chromatin modifications of defective I-elements in $\mathrm{R}^{\mathrm{H}}{ }_{3 \mathrm{~d}}$ ovaries compared with $\mathrm{R}^{\mathrm{L}}{ }_{3 \mathrm{~d}}$ ovaries.

We first compared the steady-state RNA levels of specific regions that contain defective I-elements and are affected by ancestor aging (I1667-1, I1667-2, $U$, and 2RHet), of other regions of the $42 A B$ cluster $(C L 1 A, C L 1 B)$, and of the control (vasa). By use of quantitative real-time PCR amplification after random reverse transcription of total RNA from $\mathrm{R}_{3 \mathrm{~d}}^{\mathrm{L}}$ and $\mathrm{R}^{\mathrm{H}}{ }_{3 \mathrm{~d}}$ ovaries, we were unable to detect any significant differences in the steady-state RNA levels after ancestor aging $(P>0.05)$ (Fig. 4A). We then compared the chromatin state of these regions in $\mathrm{R}_{3 \mathrm{~d}}^{\mathrm{L}}$ and $\mathrm{R}_{3 \mathrm{~d}}^{\mathrm{H}}$ ovaries by performing chromatin immunoprecipitation experiments with antibodies against chromatin marks that are assumed to reflect the transcriptional activity of these genomic loci (Fig. 4B). Again, we did not detect any significant differences in the enrichment of 
A

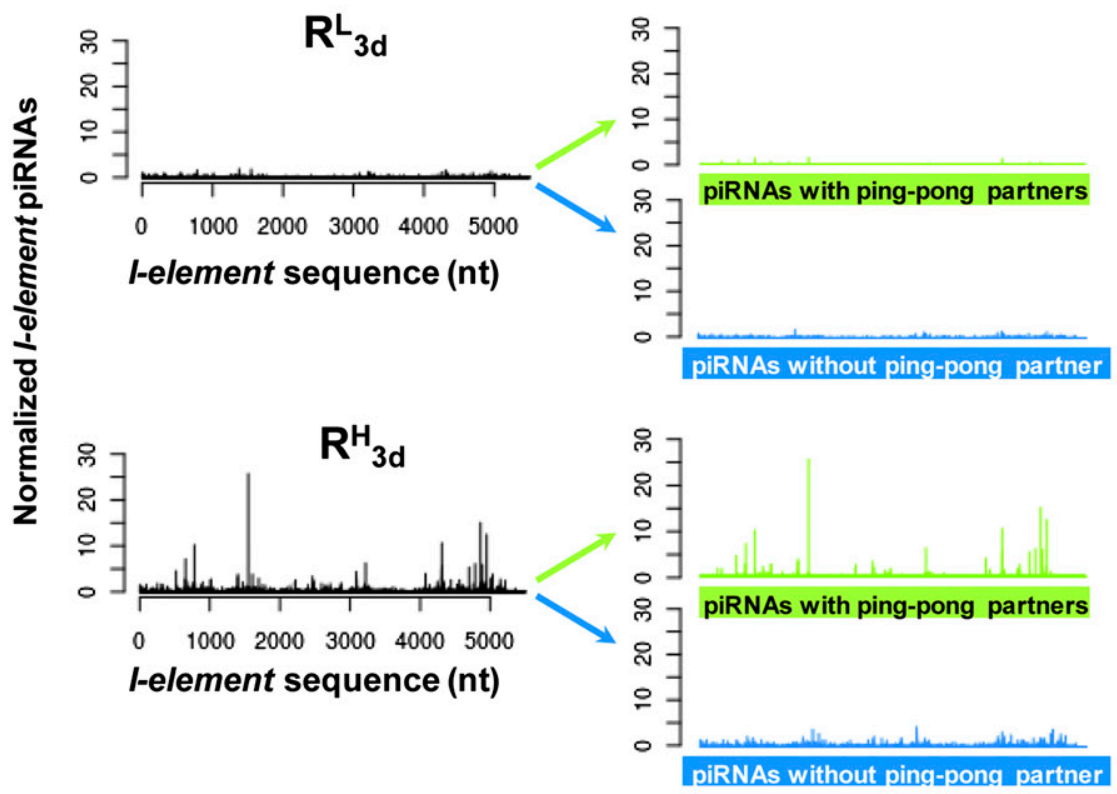

B
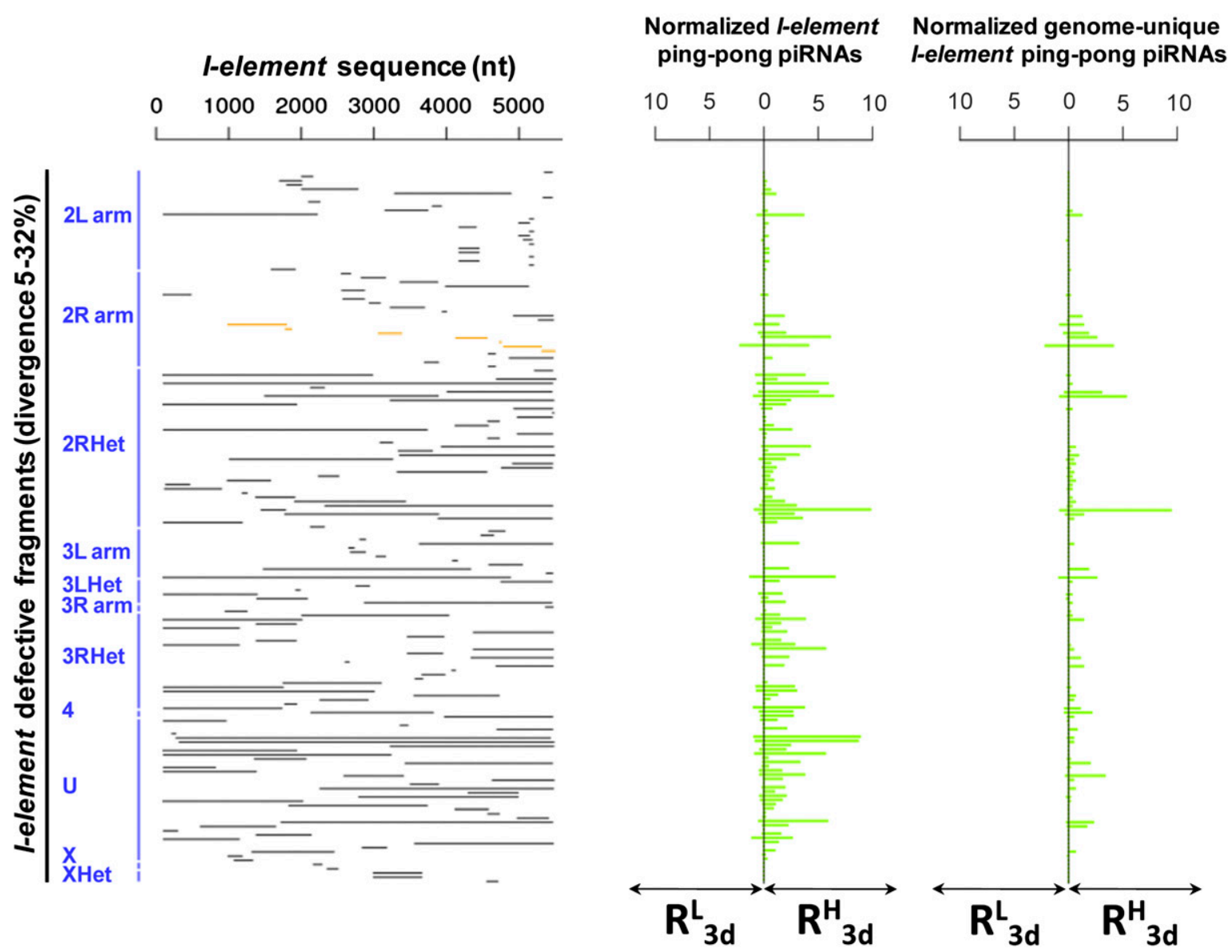

Figure 3. Evidence for ping-pong amplification between defective l-element fragments. ( $A$ ) Density profile of piRNAs matching the l-element (up to four mismatches) when they are split into piRNAs with ping-pong partners (green) and other piRNAs (blue). (B) Most of the l-element defective fragments contributed to the ping-pong-mediated amplification of I-element piRNAs in the offspring of aged ancestors. Each horizontal bar indicates one of the l-element-defective fragments annotated in the Release 5 genome sequence that were aligned to the functional $I$-element sequence and sorted by chromosomal positions (the l-element fragments located in the $42 A B$ cluster [orange]). Green bar diagrams indicate the abundance of their corresponding piRNAs with ping-pong partners in the two libraries $\left(\mathrm{R}_{3 \mathrm{H}}\right.$ and $\mathrm{R}_{3 d}^{\mathrm{L}}$ ovaries). (Left) Total piRNA levels, including read counts of piRNAs mapping to several defective I-elements weighted by their mapping number; (right) levels of piRNAs that map uniquely to each defective l-element. 

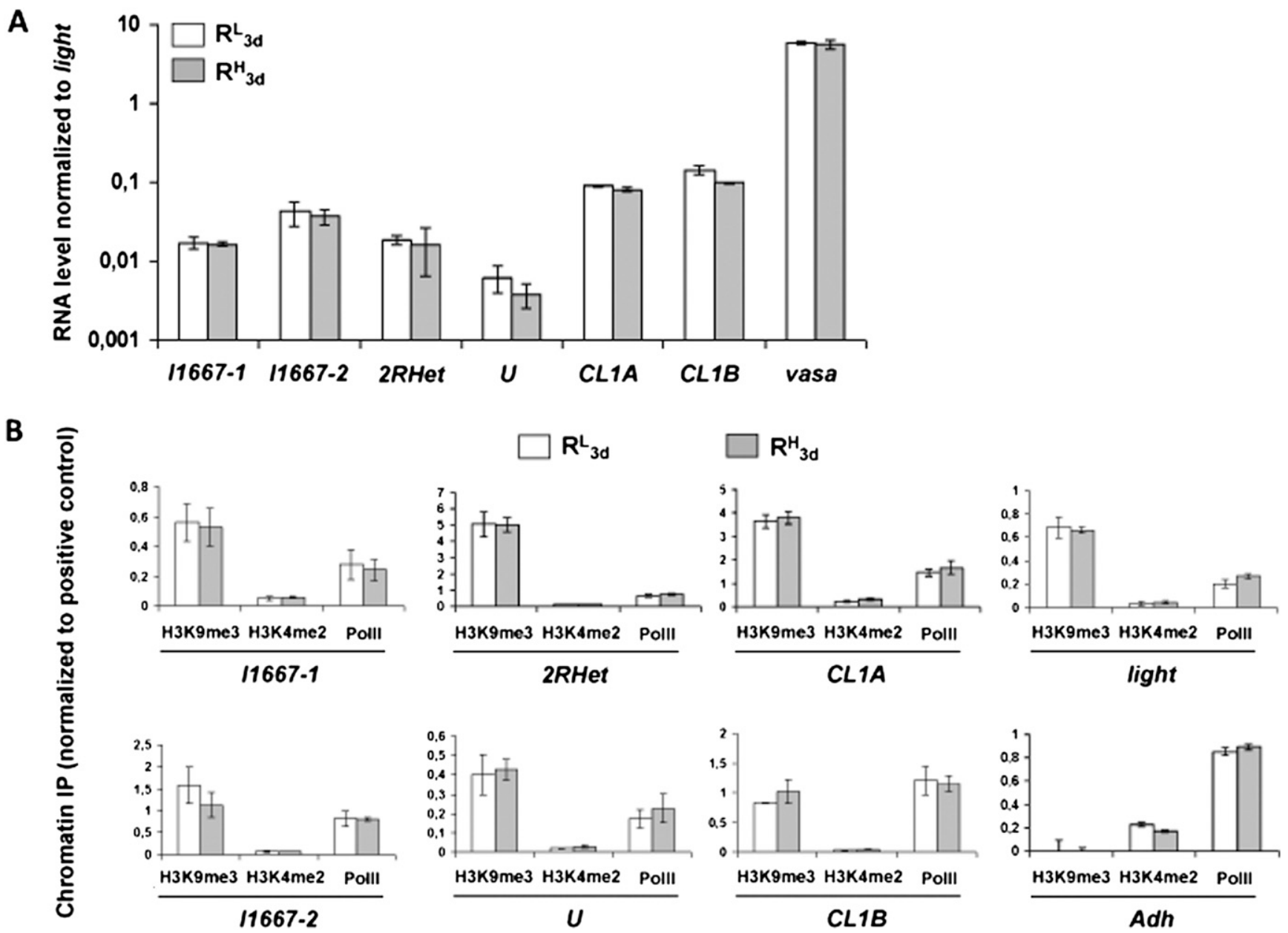

Figure 4. Transcription and chromatin marks of the l-element piRNA producers are not affected by ancestor aging. (A) Quantitative real-time PCR on randomly reverse-transcribed total RNA from $\mathrm{R}_{3 \mathrm{~d}}^{\mathrm{L}}$ (white bars) and $\mathrm{R}_{3 \mathrm{H}}$ (gray bars) ovaries. The relative levels of transcripts were measured for four genomic loci containing defective l-elements, as well as two non-l-element-containing $42 A B$ genomic loci and vasa. Values were normalized to the mRNA level of light (bars, mean $\pm \mathrm{SD}$; two-tailed Student $t$-test $P>0.05, n=3)$. (B) Chromatin immunoprecipitation assay using chromatin extracts from $\mathrm{R}^{\mathrm{L}} 3 \mathrm{~d}$ (white bars) and $\mathrm{R}_{3 \mathrm{~d}}$ (gray bars) ovaries. Eight genomic loci have been studied. $\mathrm{H} 3 \mathrm{~K} 9 \mathrm{me} 3$ immunoprecipitates were normalized to 1360 -element positive control; H3K4me2 and Pol II immunoprecipitates, to rp49 positive control (bars, mean \pm SD; two-tailed Student's $t$-test $P>0.05, n=3$ ). light and Adh were used as examples of actively transcribed genes in heterochromatic and euchromatic regions, respectively.

trimethylated histone 3 lysine 9 (H3K9me3) ( $P>0.05)$, which has been reported to be associated with piRNA cluster transcription (Rangan et al. 2011); in the enrichment of dimethylated histone 3 lysine 4 (H3K4me2; $P>0.05$ ), which has been described as a mark of transcriptionally active chromatin (Klenov et al. 2011); or in the enrichment of RNA polymerase II $(P>0.05)$, which might reflect the transcription level of a genomic region.

If ancestor aging results in an increase of the level of the piRNA precursors containing I-element fragments, then an increase of the level of piRNAs from genomic loci flanking defective I-element fragments in the same precursor should also be observed. We thus determined the amount of genome-unique piRNAs mapping to $1-\mathrm{kb}$ bins flanking the $5^{\prime}$ or $3^{\prime}$ end of annotated I-elementdefective fragments in both $\mathrm{R}_{3 \mathrm{~d}}^{\mathrm{L}}$ and $\mathrm{R}^{\mathrm{H}}{ }_{3 \mathrm{~d}}$ ovary libraries (see Methods) (Fig. 5; Supplemental Table S2; Supplemental Figs. S8, S9). First, the change of piRNA level in these bins was on average 1.1-fold, a significantly lower variation than the average of 3.3-fold increase observed for the associated defective I-elements $\left(P=10^{-8}\right)$ (Fig. 5A). Second, we did not detect any significant correlation between the changes in the piRNA levels mapping to individual I-element fragments and those of their flanking sequences (Spearman's correlation coefficient, 0.43; $P=10^{-8}$ ) (Fig. 5B). Thus, we conclude that the increase of piRNA level in $\mathrm{R}^{\mathrm{H}}{ }_{3 \mathrm{~d}}$ did not spread from the genomic loci that contain defective I-elements toward the flanking regions (that contain defective copies of many other TEs), in agreement with the observation of absence of chromatin changes after ancestor aging (Fig. 4).

Our data therefore suggest that the effect of ancestor aging on secondary piRNA production is not mediated by chromatin changes of the I-element piRNA producers.

The effect of ancestor aging is transmitted to the next generations through maternally deposited embryonic piRNAs

We then hypothesized that maternally deposited embryonic piRNAs could be responsible for the de novo ovarian amplification of secondary piRNAs, thus explaining the non-Mendelian inheritance of the age-induced defense system. In order to determine whether

\section{Genome Research www.genome.org}


A

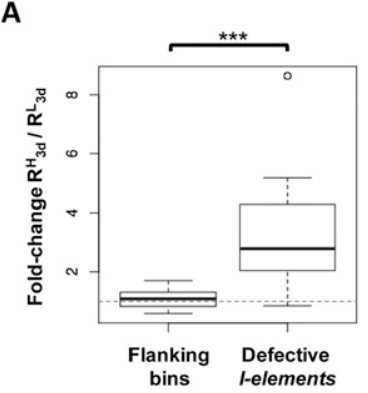

B

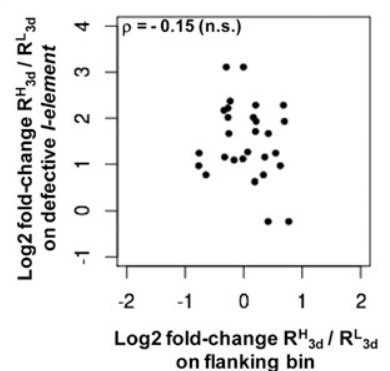

Figure 5. Ancestor aging does not affect piRNA production of genomic loci flanking defective l-element fragments. $(A)$ Boxplots display the fold change in the level of genome-unique piRNAs mapping to defective l-element fragments (right) and to associated flanking 1-kb bins (left). Only genomic loci producing at least one piRNA per million total sequenced piRNAs in both $\mathrm{R}_{3 \mathrm{~d}}^{\mathrm{L}}$ and $\mathrm{R}_{3 d}$ ovary libraries were considered. (Dashed line) The one-fold change value. Wilcoxon signed-rank test $P=10^{-8}, n=$ 26. $(B)$ Correlation between the fold change in the level of genomeunique piRNAs mapping to each defective l-element fragment and the fold change in the level of genome-unique piRNAs mapping to their associated flanking 1-kb bins (Spearman's rank correlation test: $\rho=-0.15 ; P=0.43$, $n=26)$.

the increased level of I-element piRNAs observed in $\mathrm{R}^{\mathrm{H}}{ }_{3 \mathrm{~d}}$ Ovaries was due to an increased maternal deposition of I-element piRNAs by their $\mathrm{R}^{\mathrm{H}}{ }_{25 \mathrm{~d}}$ mothers, we sequenced two additional small RNA libraries: $\mathrm{R}^{\mathrm{H}}{ }_{25 \mathrm{~d}}$ Ovaries and 0 - to 2-h-old eggs laid by $\mathrm{R}^{\mathrm{H}}{ }_{25 \mathrm{~d}}$ females.

First, we compared the sequencing data for the ovaries of the aged 25-d-old mothers $\left(\mathrm{R}^{\mathrm{H}}{ }_{25 \mathrm{~d}}\right)$ and their 3-d-old daughters $\left(\mathrm{R}_{3 \mathrm{H}}^{\mathrm{H}}\right)$. The I-element ping-pong signature detected in $\mathrm{R}^{\mathrm{H}}{ }_{3 \mathrm{~d}}$ ovaries was also present in $\mathrm{R}^{\mathrm{H}}{ }_{25 \mathrm{~d}}$ Ovaries, showing that an efficient secondary biogenesis was already active in the aged mother (data not shown). Moreover, the piRNA profile along the I-element sequence in $\mathrm{R}^{\mathrm{H}}{ }_{25 \mathrm{~d}}$ aged females was strikingly similar to that of their young daughters $\left(\mathrm{R}^{\mathrm{H}}{ }_{3 \mathrm{~d}}\right)$, but different from that of young $\mathrm{R}_{3 \mathrm{~d}}^{\mathrm{L}}$ females, the ancestors of which had never been aged (Fig. 6A). This similarity between $\mathrm{R}^{\mathrm{H}}$ mothers and daughters was confirmed by the significant correlation of the abundance of each secondary I-element piRNA sequenced in both libraries (Spearman's correlation coefficient, 0.66; $P<10^{-16}$ ) (Fig. 6B). We also noticed that the level of I-element secondary piRNAs was slightly lower in the ovaries from $\mathrm{R}^{\mathrm{H}}{ }_{3 \mathrm{~d}}$ daughters than in $\mathrm{R}^{\mathrm{H}}{ }_{25 \mathrm{~d}}$ mothers (1.9-fold decrease) (see Fig. 6C). The repetition of such a small decrease over several generations could eventually lead to the total memory loss of the acquired trait.

We then analyzed the I-element piRNA populations in eggs $\left(\mathrm{R}^{\mathrm{H}}{ }_{25 \mathrm{~d}}\right.$ eggs) laid by $\mathrm{R}^{\mathrm{H}}{ }_{25 \mathrm{~d}}$ mothers that will develop into the young $\mathrm{R}^{\mathrm{H}}{ }_{3 \mathrm{~d}}$ daughters. Although the maternally deposited piRNAs in $\mathrm{R}^{\mathrm{H}}{ }_{25 \mathrm{~d}}$ eggs did not perfectly reflect the piRNA amounts of $\mathrm{R}^{\mathrm{H}}{ }_{25 \mathrm{~d}}$ ovaries, the secondary I-element piRNA pattern was already imprinted in the eggs before any zygotic transcription (Spearman's correlation coefficient, $0.61 ; P<10^{-16}$ ) (Fig. 6D). These results indicate that the memory of the aging effect is passed to the embryo. Furthermore, this imprint was subsequently maintained until oogenesis as indicated by the comparison between the I-element piRNA patterns of $\mathrm{R}^{\mathrm{H}}{ }_{25 \mathrm{~d}}$ eggs and $\mathrm{R}_{3 \mathrm{~d}}^{\mathrm{H}}$ ovaries (Spearman's correlation coefficient, $0.62 ; P<10^{-16}$ ) (Fig. 6E). In contrast, the maternal deposition of piRNAs without a ping-pong partner seemed to have less consequence on the biogenesis of the corresponding piRNAs in the daughters' ovaries (Spearman's correlation coefficient, 0.30; $P<10^{-16}$ ) (Fig. 6E).

Overall, our data show that the memory of increased accumulation of secondary I-element piRNAs in aged ovaries is likely to be transmitted to the next generations through the increased deposition of these piRNAs in the embryonic germline at each generation.

\section{Discussion}

\section{Aging triggers the production of heterochromatic-only} l-element secondary piRNAs in the next generations

piRNAs contribute to the maintenance of genome integrity in the Drosophila female germline by repressing complementary TEs and thereby preventing dysgenesis. According to the ping-pong model, these antisense piRNAs result from the slicing of transcripts from the heterochromatic-defective TEs by ARGONAUTE3 (AGO3). AGO3 is guided by sense piRNAs that are themselves produced by the reciprocal piRNA-dependent cleavage of functional euchromatic TE RNAs (Brennecke et al. 2007; Gunawardane et al. 2007). Here we show that a ping-pong amplification can occur in the total absence of euchromatic I-elements (Fig. 2F) involving many defective I-elements (Fig. 3B, Supplemental Fig. S6).

One of the interesting questions raised by our observations is whether or not this previously unknown heterochromatic-only secondary piRNA production is specific to the I-element. We speculate that such a secondary biogenesis might also exist for the other TEs but produced only very few secondary piRNAs compared to the ping-pong loop involving heterochromatic TE precursors and TE mRNAs. This might explain the weak influence of ancestor aging on the secondary piRNA populations of all TEs, except the I-element, which is not present as a functional element in the Cha-R genome.

Once acquired upon aging treatment, this ability to produce heterochromatic-only I-element secondary piRNAs can be transmitted to the next generation of young females (Fig. 6) in a chromatin-independent manner (Fig. 4, Figure 5). The memory of ancestor aging is strong enough to promote a significant reduction of dysgenesis in the granddaughters of aged females (Fig. 1).

Khurana et al. (2011) have recently described another kind of ancestor aging memory in the P-M hybrid dysgenesis system, which is based on the mobilization of resident functional elements like the Ivk-element into piRNA clusters in aged dysgenic female ovaries. However, the P-M dysgenic aging effect is not reversible and leads to de novo piRNA production in the progeny of aged females in contrast to the piRNA-dependent aging memory here described.

\section{Maternally deposited piRNAs as vectors of short-term maternal inheritance (Fig. 7)}

In the ping-pong model as described for some TEs like $R t 1 b$, the primary piRNAs produced by heterochromatic RNA precursors initiate the secondary piRNA biogenesis (Brennecke et al. 2007; Handler et al. 2011). However, for other TEs, like the $F$ and Doc elements, the production of secondary piRNAs is much less affected by mutations of the primary piRNA pathway than in the case of $R t 1 b$, suggesting that they can rely on maternal piRNAs as ping-pong loop initiators (Malone et al. 2009; Handler et al. 2011). Whether these maternal $F$ and Doc piRNAs are essential or have only a redundant role with primary piRNAs in initiating the pingpong cycle is unknown.

The observation that, in the $\mathrm{R}^{\mathrm{L}}$ strain, the I-element secondary biogenesis pathway is very inefficient (Fig. 2F) suggests that I-element primary piRNAs are not sufficient to frequently initiate 
A

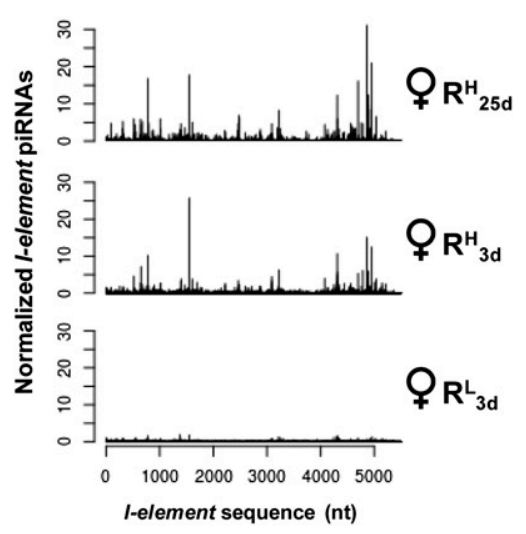

B

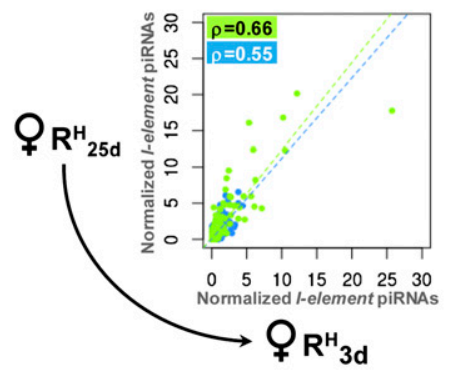

D

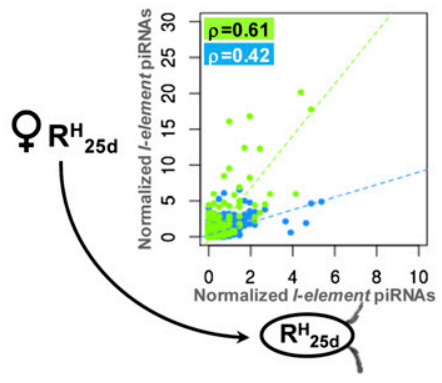

C

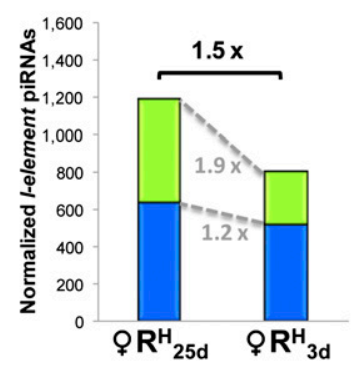

$\mathbf{E}$

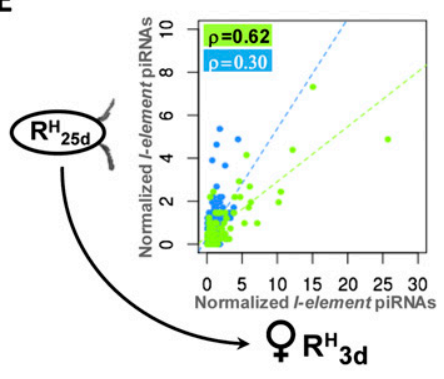

Figure 6. Maternally deposited piRNAs are the epigenetic vectors of the memory of the aging effect. (A) The density profiles of ovarian I-element piRNAs (up to four mismatches) were strikingly similar between the aged mothers $\left(\mathrm{R}^{\mathrm{H}}{ }_{25 d}\right)$ and the young daughters $\left(\mathrm{R}_{3 \mathrm{~d}}^{\mathrm{H}}\right)$, but different from those of $\mathrm{R}_{3 \mathrm{~d}}$ flies. $(B, D, E)$ Scatter plots displaying the correlations between normalized read counts for l-element piRNAs. Each point displays the normalized counts of reads collapsed to their $5^{\prime}$ end for all l-element positions. (Green) Points corresponding to ping-pong positions in the $\mathrm{R}^{\mathrm{H}}{ }_{3 \mathrm{~d}}$ ovary library. (Blue) Positions without ping-pong partner, in the $\mathrm{R}^{\mathrm{H}}{ }_{3 \mathrm{~d}}$ library. (B) Correlation for l-element ovarian piRNAs sequenced in the aged mothers and their young daughters (Spearman's rank correlation test: for ping-pong positions: $\rho=0.66$; $P<10^{-16}, n=289$; for others: $\left.\rho=0.55 ; P<10^{-16}, n=1017\right)$. (D) Correlation for I-element piRNAs sequenced in the aged mothers and their eggs (Spearman's rank correlation test: for ping-pong positions: $\rho=0.61 ; P<10^{-16}, n=151$; for others: $\rho=0.42 ; P<10^{-16}, n=528$ ). (E) Correlation between I-element piRNAs sequenced in the eggs laid by aged mothers and in the ovaries of the corresponding young daughters (Spearman's rank correlation test: for ping-pong positions: $\rho=0.62 ;<10^{-16}, n=164$; for others: $\rho=0.30 ; P<10^{-16}, n=620$ ). (C) Normalized counts of I-element piRNAs in $\mathrm{R}_{25 \mathrm{~d}}$ and $\mathrm{R}_{3 \mathrm{~d}}$ ovaries when they are split into piRNAs with sequenced ping-pong partners (green) and the others (blue). Indicated values correspond to $\mathrm{R}^{\mathrm{H}}{ }_{25 \mathrm{~d}} / \mathrm{R}^{\mathrm{H}}{ }_{3 d}$ piRNA level fold change.

the ping-pong loop. This conclusion is also supported by the finding (Fig. 3A; Supplemental Fig. S5B) that the important increase of secondary piRNAs in the $\mathrm{R}^{\mathrm{H}}$ strain did not seem to result from an increase in the putative primary piRNAs (those without sequenced ping-pong partner).

Our data therefore suggest that the lack of maternally deposited I-element piRNAs is responsible for the absence of secondary piRNAs in the $\mathrm{R}^{\mathrm{L}}$ strain. Indeed, the ping-pong signature only becomes detectable in the ovaries of young daughters after the increase in the maternal secondary piRNA pool (i.e., in the eggs laid by the aged $\mathrm{R}^{\mathrm{H}}$ stock) (Fig. 2F). Moreover, in agreement with the requirement of maternal piRNAs for the initiation of the corresponding ping-pong loop, we observed a good correlation between the amounts of secondary, but not for putative primary piRNAs deposited in the embryo and those produced in the ovary (Fig. 6E). In contrast, the maternal deposit does not seem to influence the availability of I-element defective RNA precursors as indicated by the fact that (1) the steady-state RNA levels of I-element piRNA precursors remained unchanged (Fig. 4A); (2) we failed to detect any changes in chromatin that could be responsible for an increase in transcription and/or processing of the I-element piRNA producers (Fig. 4B); and (3) the increased ability of individual I-elements to produce piRNAs did not spread to the defective TE sequences present in their flanking sequences (Fig. 5).

Our model might also explain the establishment and maintenance of P-element repression which requires both chromosomal and extrachromosomal determinants (Ronsseray et al. 1993). When P-elements are paternally inherited in the absence of the maternal extrachromosomal determinants, it takes several generations to fully repress P-element in this naïve maternal lineage (Engels 1979). Since P-element piRNAs are maternally transmitted (Brennecke et al. 2008), we propose that, as for the I-element, a maternal piRNA pool of $P$-element secondary piRNAs is required to initiate an efficient pingpong-dependent piRNA production. The progressive acquisition of the P-element repression could result from maternal deposition of steadily increasing levels of such ping-pong loop initiators at each generation.

We moreover speculate that, in the aged $\mathrm{R}^{\mathrm{H}}$ strain, the level of sense RNA precursors represents the limiting input of the secondary piRNA biogenesis, as the introduction of functional I-elements (mainly transcribed in the sense orientation) results in an additional production of I-element piRNAs in $\mathrm{SF}^{\mathrm{H}}$ females (Fig. 2B,E). This limitation, probably combined with partial maternal deposition and dilution of the maternal piRNA pool during oogenesis, could explain the reversibility of the acquired trait after several generations if the aging treatment is not maintained (Fig. 7).

Our model also explains why paternally inherited functional I-elements are not efficiently repressed in the ovaries of SF dysgenic females when the reactive mother does not provide enough initiator piRNAs. Nevertheless, the establishment of the I-element 


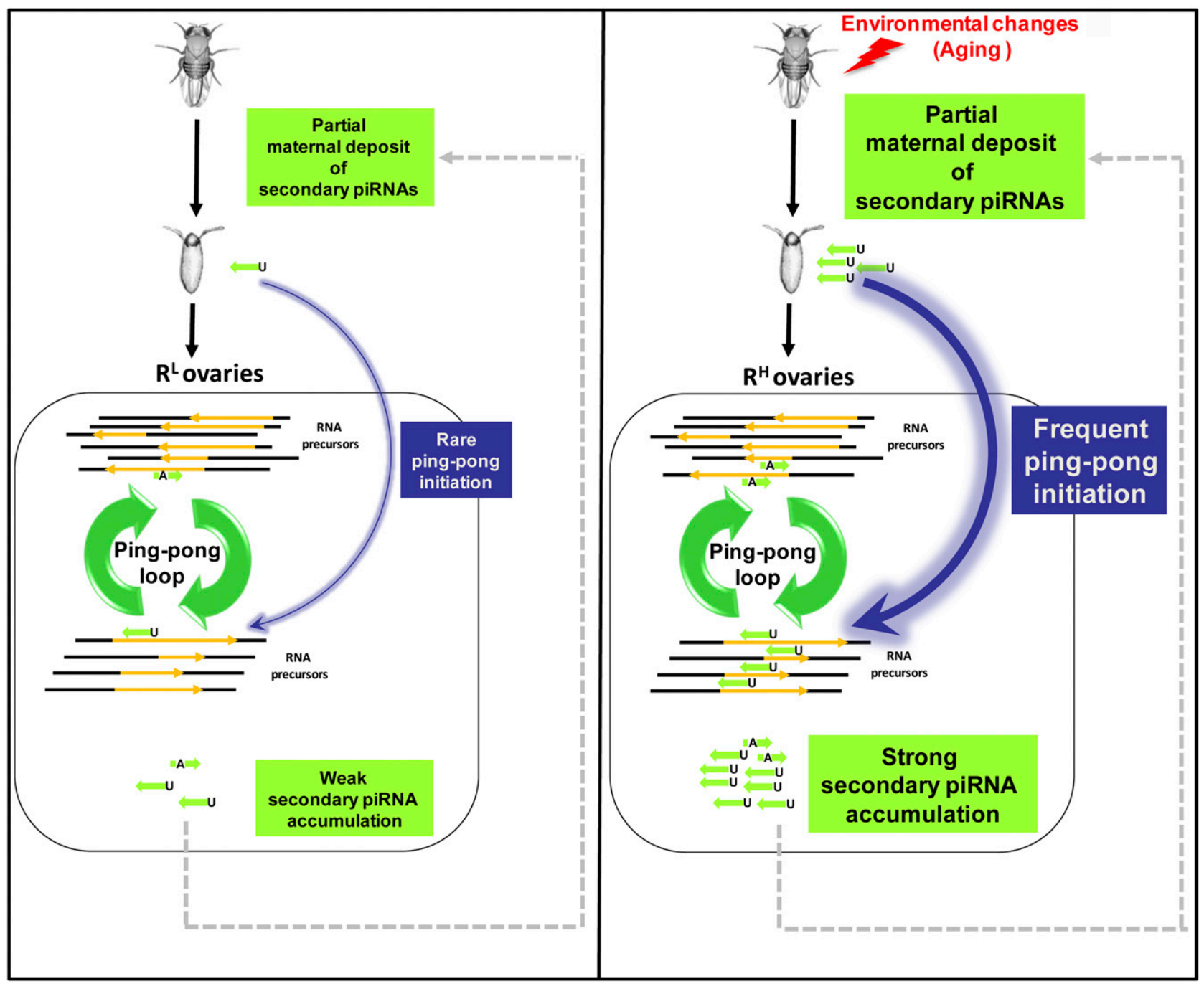

Figure 7. The amount of maternally deposited l-element piRNAs in eggs determines the amount of piRNAs in female ovaries. The left and right panels schematize the biogenesis of I-element piRNAs in the $\mathrm{R}^{\mathrm{L}}$ and $\mathrm{R}^{\mathrm{H}}$ stocks, respectively. Secondary antisense piRNAs (green arrows with uridine in the first position [1U]) are abundant in the eggs laid by aged ancestors, leading to frequent ping-pong loop initiation in ovarian germ cells (thicker blue arrow in the right panel) and, therefore, abundant ovarian secondary piRNA production and maternal piRNA deposition in the next $\mathrm{R}^{\mathrm{H}}$ generations (gray dashed line). The amount of the RNA precursors (black lines) that contain defective l-element fragments (orange arrows) is similar in both $\mathrm{R}^{\mathrm{L}}$ and $\mathrm{R}^{\mathrm{H}}$ stocks. The amount of secondary piRNAs accumulated in the ovary is therefore not limited by the amount of RNA precursors but by the amount of the maternally deposited piRNAs. Since the maternal deposit only partially reflects the secondary ovarian piRNA accumulation, the system progressively tends to the stable equilibrium of the $\mathrm{R}^{\mathrm{L}}$ stock if the environmental changes are stopped.

repression is somewhat quicker than that of $P$-element (Engels 1979), since it generally takes only two maternal generations (Pelisson and Bregliano 1987). This might be due to the fact that, unlike $\mathrm{M}$ strains, R strains can produce low levels of maternally transmitted initiator heterochromatic piRNAs. When higher amounts of piRNAs are maternally deposited, as in the $\mathrm{R}^{\mathrm{H}}$ lineage described here, almost full repression can be reached in the first generation $\left(\mathrm{SF}^{\mathrm{H}}\right.$ females). Note however that, as recently reported (Khurana et al. 2011), P-M dysgenic females, lacking any P-element piRNA can, at the end of their life, produce enough piRNAs to completely repress their $P$-elements.

\section{Long-term inheritance of the piRNA nucleotide-strand bias}

Cloning and sequencing of piRNAs associated with PIWI proteins revealed protein-dependent nucleotide and strand bias. In the
Drosophila ovaries, the PIWI and AUBERGINE (AUB) proteins preferentially load antisense $1 \mathrm{U}$ piRNAs coming from heterochromatic transcripts, and the AGO3 protein mainly loads sense $10 \mathrm{~A}$ piRNAs derived from the cleavage by AUB of functional TE transcripts. The PIWI and AUB $1 \mathrm{U}$ bias is probably due to their $1 \mathrm{U}$ affinity, as shown for their SIWI silkworm homolog (Kawaoka et al. 2011b). The molecular basis for the PIWI and AUB antisense bias is not thoroughly understood.

In an attempt to explain these strand biases, it was proposed that functional euchromatic sense transcripts are physically isolated in specific subcellular domains where they would be selectively targeted by complementary AUB-associated piRNAs and presented to AGO3 for piRNA loading. Such domains might correspond, for instance, to the mouse pi-bodies, where TE transcriptderived piRNAs appear to be preferentially loaded by the PIWIL2 (also known as MILI) protein (Aravin et al. 2008). 
Here, we show that a ping-pong signature could be readily detected in the absence of functional euchromatic I-elements (Fig. 2F). Surprisingly, in these R ovaries, only sense I-element ping-pong piRNAs exhibit a 10A bias (Supplemental Fig. S5C). As the secondary biogenesis in $\mathrm{R}$ strains occurs between many heterochromatic transcripts that contain various defective I-element fragments in any orientation, how could AGO3 discriminate piRNAs, which are sense according to the I-element? An exciting hypothesis is that the bias originated a very long time ago during the first invasion of the Drosophila genome by functional I-elements. As PIWI and AUB localize to the posterior pole of the oocyte where the primordial germ cells of the embryo are formed (Harris and Macdonald 2001; Megosh et al. 2006), AUBassociated piRNAs were already maternally deposited as antisense $1 \mathrm{U}$ piRNAs, initiating the production of complementary sense 10A AGO3-associated piRNAs. Since then, the bias would have been faithfully transmitted in an egg-hen cycle.

\section{Why do aged ovaries produce more l-element secondary piRNAs?}

In this work, we took advantage of an increased level of I-element piRNAs in aged ovaries to study how this initial change is maternally inherited. However, we can only speculate about the mechanisms whereby aging itself can affect I-element piRNA biogenesis. In particular, we do not know whether a specific germ cell and/or oogenesis stage translates the effect of aging to I-element ovarian piRNAs. A priori, aging could affect the physiology of any ovarian tissue. Even germinal stem cells (GSCs) were reported to age and die after a number of asymmetric divisions (Xie and Spradling 2000; Pan et al. 2007) generating one GSC and one cystoblast (i.e., the differentiated precursor of the future egg) (Spradling et al. 2001).

In our reactive strain-model, I-element piRNA biogenesis could be limited by the lack of both maternal (secondary) and zygotic (primary) initiator piRNAs. Aging is known to affect mitochondrial physiology (Schwarze et al. 1998; Das et al. 2001). Potential relationships have been recently described between mitochondria and primary piRNA biogenesis (Haase et al. 2010; Olivieri et al. 2010; Saito et al. 2010; Huang et al. 2011; Watanabe et al. 2011). Hence, a putatively improved primary piRNA production might explain why aged ovaries produce more secondary I-element piRNAs.

Alternatively, the increased piRNA production might not be directly due to cellular aging, but rather to the several cell divisions required to generate aged GSCs, like the several fly generations that are needed for the progressive establishment of the P-element repression. According to this hypothesis, the first ping-pong cycle would be initiated by maternally deposited piRNAs in the primordial germ cells, as described in the silkworm (Kawaoka et al. 2011a). Then, a round of secondary piRNA production, initiated by the piRNA pool inherited from the mother cell, would occur postmitotically in each GSC. A challenge for the future will be to test this cellular memory hypothesis.

\section{Methods}

\section{Drosophila stocks}

Flies were grown on standard Drosophila food (Gans et al. 1975) at $23^{\circ} \mathrm{C}$.

The Cha reactive strain was initiated with flies collected in the 1950s in Charolles (France). The Cha-R flies are devoid of any euchromatic and/or heterochromatic functional I-element (Bucheton et al. 1984; Vaury et al. 1989; Chambeyron et al. 2002).

The Cha-I inducer stock that has the same genotype as the Cha strain results from the transposition of I-elements in the Cha reactive strain by outcrossing according to the method described by Pelisson and Bregliano (1987). The Cha-R and the Cha-I strains are therefore isogenic except for the presence of functional I-elements in Cha-I.

\section{RNA in situ hybridization}

In situ hybridization experiments were performed on ovaries from 3-d-old $\mathrm{SF}^{\mathrm{L}}$ and $\mathrm{SF}^{\mathrm{H}}$ flies according to the method described by Chambeyron et al. (2008) using a 2.9-kb I-element antisense riboprobe corresponding to T7 in vitro transcription of a PCR fragment obtained with pSPT19-I plasmid (Chaboissier et al. 1990). Briefly, hybridization was performed overnight at $55^{\circ} \mathrm{C}$ and washing at $55^{\circ} \mathrm{C}$. The I-element antisense riboprobe was labeled using the Biotin RNA labeling mix (Roche). The anti-biotin antibody was labeled with FITC (Vector laboratories; dilution 1/200). Ovaries were counterstained with DAPI. Images were captured on a Zeiss LSM510 META confocal microscope.

\section{Measurements of hatching percentages}

Fertility of the $\mathrm{SF}^{\mathrm{L}}$ and $\mathrm{SF}^{\mathrm{H}}$ crosses was determined using 24-h eggs laid by 3 -d-old fertilized females after a 48 -h incubation period at $25^{\circ} \mathrm{C}$. Measurements of 33 vials were scored for each cross.

\section{Chromatin immunoprecipitation and qPCR analysis}

Fly ovaries were dissected into ice Schneider's insect medium (Sigma) and homogenized in $500 \mu \mathrm{L}$ buffer A (60 mM KCl, $15 \mathrm{mM}$ $\mathrm{NaCl}, 15 \mathrm{mM}$ Hepes, $0.5 \%$ Triton-X100, $10 \mathrm{mM}$ sodium butyrate, complete "mini" EDTA-free protease inhibitor tablets; Roche) with $1.8 \%$ formaldehyde (Thermo Scientific) at room temperature (RT) using a Douncer with pestle "tight." Total time for homogenization and cross-linking was exactly $10 \mathrm{~min}$. Glycine was added to $125 \mathrm{mM}$ final, and samples were incubated $3 \mathrm{~min}$ at RT and then chilled on ice. Samples were centrifuged $\left(5 \mathrm{~min}, 4000 \mathrm{~g}\right.$ at $\left.4^{\circ} \mathrm{C}\right)$, and pellets were resuspended in buffer A with $125 \mathrm{mM}$ glycine, incubated 5 min with agitation, and then centrifuged. The washing step was repeated two times with buffer A and another time with lysis buffer (140 mM NaCl, $15 \mathrm{mM}$ Hepes, $1 \mathrm{mM}$ EDTA, $0.5 \mathrm{mM}$ EGTA, $1 \%$ Triton-X100, $0.1 \%$ sodium deoxycholate, $10 \mathrm{mM}$ sodium butyrate, complete "mini" EDTA-free protease inhibitor tablets). Pellets were resuspended in $200 \mu \mathrm{L}$ lysis buffer with $0.5 \%$ SDS, $0.5 \%$ N-laurosylsarcosine and incubated $3 \mathrm{~h}$ at $4^{\circ} \mathrm{C}$ on a rotating wheel. Samples were sonicated with a Bioruptor (Diagenode; high level, $30 \mathrm{sec}$ on, $30 \mathrm{sec}$ off, repeated 12 times with resuspension after six times) and centrifuged $\left(10 \mathrm{~min}, 20,000 \mathrm{~g}\right.$ at $\left.4^{\circ} \mathrm{C}\right)$. Lysates were then $5 \times$ diluted to $0.1 \%$ SDS with lysis buffer. Protein $\mathrm{G}$ dynabeads (Invitrogen) were washed in PBS- $0.1 \mathrm{mg} / \mathrm{mL}$ BSA three times, added to lysates and incubated $3 \mathrm{~h}$ at $4^{\circ} \mathrm{C}$ on a rotating wheel. Protein $G$ dynabeads were then replaced by dynabeads coupled with antibody (anti-Pol II clone 4H8 [ab5408, Abcam], anti-H3K4me2 [no. 07-030, Millipore], and anti-H3K9me3 [ab8898, Abcam]) according to the manufacturer's instructions and incubated overnight at $4^{\circ} \mathrm{C}$ on a rotating wheel. After incubation, beads were washed seven times for $10 \mathrm{~min}$ at $4^{\circ} \mathrm{C}$ : two times in RIPA buffer (150 mM NaCl, $50 \mathrm{mM}$ Tris at $\mathrm{pH}$ 8.1, 0.1\% SDS, $1 \%$ $\mathrm{NP} 40)$, one time in high-salt buffer $(500 \mathrm{mM} \mathrm{NaCl}, 50 \mathrm{mM}$ Tris at pH 8.1, 0.1\% SDS, $1 \%$ NP40), one time in LiCl buffer ( $250 \mathrm{mM} \mathrm{LiCl}$, $50 \mathrm{mM}$ Tris at $\mathrm{pH} 8.1,0.5 \%$ sodium deoxycholate), and three times in Tris-EDTA (TE) (10 mM Tris at pH 8, $0.1 \mathrm{mM}$ EDTA). Chromatin

\section{Genome Research \\ www.genome.org}


was eluted by adding $100 \mu \mathrm{L}$ of elution buffer 1 (10 mM EDTA, 1\% SDS, $50 \mathrm{mM}$ Tris- $\mathrm{HCl}$ at $\mathrm{pH} 8$ ) and incubated $15 \mathrm{~min}$ at $65^{\circ} \mathrm{C}$ under vigorous shaking. Elution was repeated with $150 \mu \mathrm{L}$ of elution buffer $2(0.67 \%$ SDS in TE). The two supernatants were pooled and cross-linking of each immunoprecipitated complex was reversed by incubation of the eluate during $6 \mathrm{~h}$ at $65^{\circ} \mathrm{C}$ in a mix containing $1 \%$ SDS and $200 \mathrm{mM} \mathrm{NaCl}$. After digestion with RNase A at $37^{\circ} \mathrm{C}$ for $1 \mathrm{~h}$ and proteinase $\mathrm{K}$ for $2 \mathrm{~h}$ at $50^{\circ} \mathrm{C}$, DNA was purified by phenol-chloroform extraction (MP Biomedicals) and precipitated with ethanol. Biological triplicates were generated for each experiment and subjected to quantitative real-time PCR performed on LightCycler480 (Roche) using SYBR Green I Master (Roche). The levels of DNA in the immunoprecipitates for anti-Pol II and anti-H3K4me2 antibodies were normalized to $r p 49$-positive control and to 1360-element for the anti-H3K9me3 antibody.

\section{RNA extraction and qRT-PCR}

Quantitative PCR was performed on LightCycler480 (Roche) using SYBR Green I Master (Roche). Total RNA was isolated from 50 ovary pairs by TRIzol extraction (Invitrogen). RNA was treated with TURBO DNase (Ambion) according to the manufacturer's instructions. cDNA was synthesized by reverse transcription of $2 \mu \mathrm{g}$ total RNA using SuperScript II Reverse Transcriptase (Invitrogen) and random hexamer primers. Quantitative PCR was realized on LightCycler480 (Roche) using SYBR Green I Master (Roche). Each experiment was performed in biological triplicates with technical duplicates. RNA levels were normalized to the mRNA level of light.

\section{Bioinformatic analysis of small RNA libraries}

Our pipeline was based on the analytical strategy which has been previously described in Brennecke et al. (2008) and Handler et al. (2011; see Supplemental Methods). To quantify the non-I-elementderived piRNAs that flank defective I-elements, we first retrieved from the UCSC repeatmasker track genomic positions of all defective I-element fragments that were at least $1 \mathrm{~kb}$ apart. We then defined a 1-kb bin flanking each end of these defective I-elements and retrieved all piRNA sequences mapping uniquely to them. Annotation of defective TEs located in flanking bins was performed using the UCSC RepeatMasker track.

\section{Statistical analyses}

All statistical analyses were performed using R software (R Development Core Team 2010; http://www.R-project.org). For comparison of sample means (Figs. 1B, 4A,B, 5A; Supplemental Fig. S4), $P$-values were calculated using two-tailed Student $t$-test for samples displaying normal distribution (tested with Shapiro-Wilk test) and variance homogeneity (tested with Levene's test) and using Wilcoxon signed-rank test for others. For correlation analyses (Figs. 5B, 6B-E), $P$-values were calculated using Spearman's rank correlation test to avoid outlier effects.

\section{Data access}

Small RNA libraries generated in this study are available via the NCBI Gene Expression Omnibus (GEO) (http://www.ncbi.nlm. nih.gov/geo/) under accession no. GSE34506, data sets GSM850349 to GSM850354.

\section{Acknowledgments}

We thank Alain Bucheton for unfailing support throughout this work, Nicoletta Corradini for her cDNA legacy, the Genoscope
(CEA, Paris, France) and MGX (Montpellier, France) sequencing services, Julius Brennecke for his helpful discussions, Hervé Seitz for bioinformatic support, and Ned Lamb for critical reading of the manuscript. We thank Mikiko C. Siomi, Julius Brennecke, and Krzysztof Rogowski for antibodies. This work was funded by grants from Genoscope (Appel à proposition 2009-2010-Projet n8), l'Association contre le cancer (ARC JR/AD/DMV-09/2/5007), ANR Jeunes chercheurs (ESSOR- JCJC-1604 01), and grants from the CNRS. T.G. was supported by a fellowship from the French "Ministère de la Recherche et de l'Enseignement Supérieur"; C.A. by the Fondation pour la Recherche Médicale (FRM); and V.S. by the Association pour la Recherche sur le Cancer (ARC).

Author contributions: T.G., C.B., and B.M. performed the experiments. C.A. performed all bioinformatic analysis, assisted by discussions with V.S. and A.P. A.P. and S.C. designed the research. C.A., A.P., T.G., and S.C. wrote the manuscript with the help of discussions with B.M., V.S., and C.B.

\section{References}

Aravin AA, Sachidanandam R, Bourc'his D, Schaefer C, Pezic D, Toth KF, Bestor T, Hannon GJ. 2008. A piRNA pathway primed by individual transposons is linked to de novo DNA methylation in mice. Mol Cell 31: 785-799.

Biemont C, Vieira C. 2006. Genetics: Junk DNA as an evolutionary force. Nature 443: 521-524.

Brennecke J, Aravin AA, Stark A, Dus M, Kellis M, Sachidanandam R, Hannon GJ. 2007. Discrete small RNA-generating loci as master regulators of transposon activity in Drosophila. Cell 128: 1089-1103.

Brennecke J, Malone CD, Aravin AA, Sachidanandam R, Stark A, Hannon GJ. 2008. An epigenetic role for maternally inherited piRNAs in transposon silencing. Science 322: 1387-1392.

Bucheton A. 1978. Non-Mendelian female sterility in Drosophila melanogaster: Influence of ageing and thermic treatments. I. Evidence for a partly inheritable effect of these two factors. Heredity 41: 357-369.

Bucheton A. 1979. Non-Mendelian female sterility in Drosophila melanogaster: Influence of aging and thermic treatments. III. Cumulative effects induced by these factors. Genetics 93: 131-142.

Bucheton A, Lavige JM, Picard G, L'Heritier P. 1976. Non-mendelian female sterility in Drosophila melanogaster: quantitative variations in the efficiency of inducer and reactive strains. Heredity 36: 305-314.

Bucheton A, Paro R, Sang HM, Pelisson A, Finnegan DJ. 1984. The molecular basis of I-R hybrid dysgenesis in Drosophila melanogaster: identification, cloning, and properties of the I factor. Cell 38: 153-163.

Bucheton A, Vaury C, Chaboissier MC, Abad P, Pelisson A, Simonelig M. 1992. I elements and the Drosophila genome. Genetica 86: 175-190.

Bucheton A, Busseau I, Teninges D. 2002. I element in Drosophila melanogaster. In Mobile DNA II (ed. NL Craig et al.), pp. 796-812. ASM, Washington, DC.

Chaboissier MC, Busseau I, Prosser J, Finnegan DJ, Bucheton A. 1990. Identification of a potential RNA intermediate for transposition of the LINE-like element I factor in Drosophila melanogaster. EMBO J 9: 35573563.

Chambeyron S, Bucheton A. 2005. I elements in Drosophila: In vivo retrotransposition and regulation. Cytogenet Genome Res 110: 215-222.

Chambeyron S, Bucheton A, Busseau I. 2002. Tandem UAA repeats at the 3'end of the transcript are essential for the precise initiation of reverse transcription of the I factor in Drosophila melanogaster. J Biol Chem 277: 17877-17882.

Chambeyron S, Popkova A, Payen-Groschene G, Brun C, Laouini D, Pelisson A, Bucheton A. 2008. piRNA-mediated nuclear accumulation of retrotransposon transcripts in the Drosophila female germline. Proc Natl Acad Sci 105: 14964-14969.

Das N, Levine RL, Orr WC, Sohal RS. 2001. Selectivity of protein oxidative damage during aging in Drosophila melanogaster. Biochem J 360: 209216.

Engels WR. 1979. Hybrid dysgenesis in Drosophila melanogaster: Rules of inheritance of female sterility. Genet Res 33: 219-236.

Gans M, Audit C, Masson M. 1975. Isolation and characterization of sexlinked female-sterile mutants in Drosophila melanogaster. Genetics 81: 683-704.

Gunawardane LS, Saito K, Nishida KM, Miyoshi K, Kawamura Y, Nagami T, Siomi H, Siomi MC. 2007. A slicer-mediated mechanism for repeatassociated siRNA 5' end formation in Drosophila. Science 315: 15871590 . 
Haase AD, Fenoglio S, Muerdter F, Guzzardo PM, Czech B, Pappin DJ, Chen C, Gordon A, Hannon GJ. 2010. Probing the initiation and effector phases of the somatic piRNA pathway in Drosophila. Genes Dev 24: 2499-2504.

Handler D, Olivieri D, Novatchkova M, Gruber FS, Meixner K, Mechtler K, Stark A, Sachidanandam R, Brennecke J. 2011. A systematic analysis of Drosophila TUDOR domain-containing proteins identifies Vreteno and the Tdrd12 family as essential primary piRNA pathway factors. EMBO J 30: 3977-3993.

Harris AN, Macdonald PM. 2001. aubergine encodes a Drosophila polar granule component required for pole cell formation and related to eIF2C. Development 128: 2823-2832.

Huang H, Gao Q, Peng X, Choi SY, Sarma K, Ren H, Morris AJ, Frohman MA 2011. piRNA-associated germline nuage formation and spermatogenesis require MitoPLD profusogenic mitochondrial-surface lipid signaling. Dev Cell 20: 376-387.

Kawaoka S, Arai Y, Kadota K, Suzuki Y, Hara K, Sugano S, Shimizu K, Tomari Y, Shimada T, Katsuma S. 2011a. Zygotic amplification of secondary piRNAs during silkworm embryogenesis. RNA 17: 1401-1407.

Kawaoka S, Izumi N, Katsuma S, Tomari Y. 2011b. 3' end formation of PIWIinteracting RNAs in vitro. Mol Cell 43: 1015-1022.

Khurana JS, Wang J, Xu J, Koppetsch BS, Thomson TC, Nowosielska A, Li C, Zamore PD, Weng Z, Theurkauf WE. 2011. Adaptation to P element transposon invasion in Drosophila melanogaster. Cell 147: 1551-1563.

Klattenhoff C, Xi H, Li C, Lee S, Xu J, Khurana JS, Zhang F, Schultz N, Koppetsch BS, Nowosielska A, et al. 2009. The Drosophila HP1 homolog Rhino is required for transposon silencing and piRNA production by dual-strand clusters. Cell 138: 1137-1149.

Klenov MS, Sokolova OA, Yakushev EY, Stolyarenko AD, Mikhaleva EA, Lavrov SA, Gvozdev VA. 2011. Separation of stem cell maintenance and transposon silencing functions of Piwi protein. Proc Natl Acad Sci 108: 18760-18765.

Lander ES, Linton LM, Birren B, Nusbaum C, Zody MC, Baldwin J, Devon K, Dewar K, Doyle M, FitzHugh W, et al. 2001. Initial sequencing and analysis of the human genome. Nature 409: 860-921.

Lau NC, Robine N, Martin R, Chung WJ, Niki Y, Berezikov E, Lai EC. 2009. Abundant primary piRNAs, endo-siRNAs, and microRNAs in a Drosophila ovary cell line. Genome Res 19: 1776-1785.

Malone CD, Brennecke J, Dus M, Stark A, McCombie WR, Sachidanandam R, Hannon GJ. 2009. Specialized piRNA pathways act in germline and somatic tissues of the Drosophila ovary. Cell 137: 522-535.

Megosh HB, Cox DN, Campbell C, Lin H. 2006. The role of PIWI and the miRNA machinery in Drosophila germline determination. Curr Biol 16: 1884-1894.

Olivieri D, Sykora MM, Sachidanandam R, Mechtler K, Brennecke J. 2010. An in vivo RNAi assay identifies major genetic and cellular requirement for primary piRNA biogenesis in Drosophila. EMBO J 29: 3301-3317.
Pan L, Chen S, Weng C, Call G, Zhu D, Tang H, Zhang N, Xie T. 2007. Stem cell aging is controlled both intrinsically and extrinsically in the Drosophila ovary. Cell Stem Cell 1: 458-469.

Pelisson A, Bregliano JC. 1987. Evidence for rapid limitation of the I element copy number in a genome submitted to several generations of I-R hybrid dysgenesis in Drosophila melanogaster. Mol Gen Genet 207: 306-313.

$\mathrm{R}$ Development Core Team. 2010. R: A language and environment for statistical computing. R Foundation for Statistical Computing, Vienna, Austria.

Rangan P, Malone CD, Navarro C, Newbold SP, Hayes PS, Sachidanandam R, Hannon GJ, Lehmann R. 2011. piRNA production requires heterochromatin formation in Drosophila. Curr Biol 21: 1373-1379.

Ronsseray S, Lemaitre B, Coen D. 1993. Maternal inheritance of P cytotype in Drosophila melanogaster: A "pre-P cytotype" is strictly extrachromosomally transmitted. Mol Gen Genet 241: 115-123.

Saito K, Siomi MC. 2010. Small RNA-mediated quiescence of transposable elements in animals. Dev Cell 19: 687-697.

Saito K, Ishizu H, Komai M, Kotani H, Kawamura Y, Nishida KM, Siomi H, Siomi MC. 2010. Roles for the Yb body components Armitage and $\mathrm{Yb}$ in primary piRNA biogenesis in Drosophila. Genes Dev 24: 2493-2498.

Schwarze SR, Weindruch R, Aiken JM. 1998. Oxidative stress and aging reduce COX I RNA and cytochrome oxidase activity in Drosophila. Free Radic Biol Med 25: 740-747.

Senti KA, Brennecke J. 2010. The piRNA pathway: A fly's perspective on the guardian of the genome. Trends Genet 26: 499-509.

Siomi MC, Sato K, Pezic D, Aravin AA. 2011. PIWI-interacting small RNAs: The vanguard of genome defence. Nat Rev Mol Cell Biol 12: 246-258.

Spradling A, Drummond-Barbosa D, Kai T. 2001. Stem cells find their niche. Nature 414: $98-104$

Vaury C, Bucheton A, Pelisson A. 1989. The $\beta$ heterochromatic sequences flanking the I elements are themselves defective transposable elements. Chromosoma 98: 215-224.

Vaury C, Abad P, Pelisson A, Lenoir A, Bucheton A. 1990. Molecular characteristics of the heterochromatic I elements from a reactive strain of Drosophila melanogaster. J Mol Evol 31: 424-431.

Watanabe T, Chuma S, Yamamoto Y, Kuramochi-Miyagawa S, Totoki Y, Toyoda A, Hoki Y, Fujiyama A, Shibata T, Sado T, et al. 2011. MITOPLD is a mitochondrial protein essential for nuage formation and piRNA biogenesis in the mouse germline. Dev Cell 20: 364-375.

Xie T, Spradling AC. 2000. A niche maintaining germ line stem cells in the Drosophila ovary. Science 290: 328-330.

Zamparini AL, Davis MY, Malone CD, Vieira E, Zavadil J, Sachidanandam R, Hannon GJ, Lehmann R. 2011. Vreteno, a gonad-specific protein, is essential for germline development and primary piRNA biogenesis in Drosophila. Development 138: 4039-4050.

Received December 16, 2011; accepted in revised form April 19, 2012. 


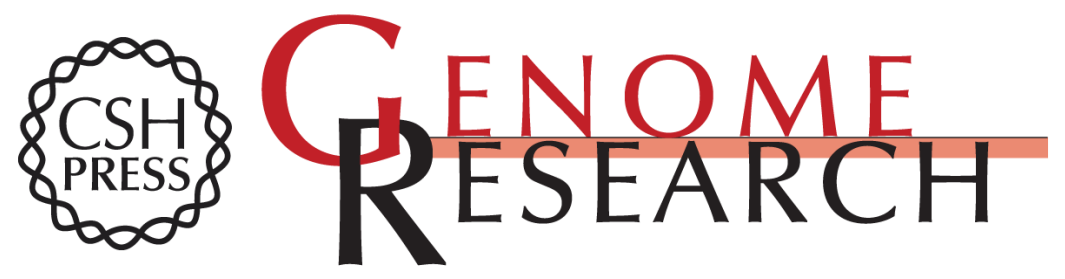

\section{piRNA-mediated transgenerational inheritance of an acquired trait}

Thomas Grentzinger, Claudia Armenise, Christine Brun, et al.

Genome Res. 2012 22: 1877-1888 originally published online May 3, 2012

Access the most recent version at doi:10.1101/gr.136614.111

Supplemental
Material

References

Creative

Commons

License

Email Alerting Service
http://genome.cshlp.org/content/suppl/2012/08/20/gr.136614.111.DC1

This article cites 46 articles, 12 of which can be accessed free at: http://genome.cshlp.org/content/22/10/1877.full.html\#ref-list-1

This article is distributed exclusively by Cold Spring Harbor Laboratory Press for the first six months after the full-issue publication date (see

http://genome.cshlp.org/site/misc/terms.xhtml). After six months, it is available under a Creative Commons License (Attribution-NonCommercial 3.0 Unported License), as described at http://creativecommons.org/licenses/by-nc/3.0/.

Receive free email alerts when new articles cite this article - sign up in the box at the top right corner of the article or click here.

\section{Affordable, Accurate Sequencing.}

To subscribe to Genome Research go to:

https://genome.cshlp.org/subscriptions 